\title{
Saudi Viewers' Perceptions of Attack on Titan Japanese Animation Online Series
}

\author{
Afnan Qutub ${ }^{1} \&$ Merfat Alardawi ${ }^{1}$ \\ ${ }^{1}$ College of Media and Communication, Journalism and Digital Media Department, King Abdulaziz University, \\ Jeddah, Saudi Arabia \\ Correspondence: Afnan Qutub. E-mail: aqutub@kau.edu.sa
}

Received: October 28, 2021

Accepted: December 6, 2021

Online Published: December 30, 2021

doi:10.5539/ass.v18n1p65

URL: https://doi.org/10.5539/ass.v18n1p65

\begin{abstract}
This quantitative study examines Saudi viewers' perceptions of the Japanese anime Attack on Titan. Data collection was undertaken by means of an online survey of 346 viewers of the animation, aged between fourteen and thirty-eight. The results indicated that the most popular characters were Levi, Eren, and Mikasa, with the least liked being the Armorer Titan, the Female Titan, Sasha, and Christa. The research found that the participants were attracted to scenes including fights between human and Titans, flying blood, and dialogue. The viewers expressed an interest in the unique scenario of the series, as well as each character's tone of voice and facial expression. Finally, the hypothesis testing (Ho) of viewers' tendency to like characters based on gender was accepted as confirmed by the 2-tail test (.042), i.e. the participants tended to prefer male characters. This study recommends that future research applies content analysis to provide further insights into the reasons behind the identified preference for male characters.
\end{abstract}

Keywords: Japanese Animation, Attack on Titan, Flow theory, Saudi Female Viewers, characters

\section{Introduction}

Japanese animation has, since the 1940s, spread from Asian countries (e.g., China, Korea, Thailand Singapore, Hong Kong, India) to Western regions (e.g., the United States of America, Britain, Canada, Germany, France) (Tongdhamachart, 2015). Japanese animation has recently become a worldwide phenomenon, facilitated by digital networks such as Netflix (Steine, 2019). Tongdhamachart (2015) reported that, by 2013, the global animation industry was worth USD 222 billion and that 'major animation markets were the United States, Canada, Japan, China, France, Britain, Korea and Germany, growing around 7\% year on year.' (Tongdhamachart, 2015, p. 129). Furthermore, Japanese animation showed a growth of 767.6 billion yen in 2016 (Stein, 2019), with AJA (2018) stating that the United States of America signed around 200 contracts, with European countries signing eighty contracts.

There are a number of interpretations of the terms "anime" and "animation", leading to difficulties in making a clear differentiation between the two. During the 1970s, the term "Japanimation" initially emerged in English, with Ruh (2014) noting that "the term "Japanimation" began to fall from popularity nearly a decade later — one reason was that it got too easily twisted into a racially derogatory term by detractors (e.g., "Jap animation")' (2014:165). The term "anime" arose during the late 1980s and the early 1990s (Ruh, 2014), with Brown (2006) indicating that the definition emerged from the act of watching anime onscreen and, as such, the word "anime" is dependent on the situation.

Thus, anime does not necessarily refer to animation from a particular country, but rather to a method of positioning images onscreen, along with how audiences communicate with such details. These broad definitions lead to a number of difficulties in determining the category of Japanese animation or anime, which include: (1) "Japanese animated films" (Lovegren, 2003; Natsume, 2000); (2) print-partnerships, such as "manga or comic" (Lankshear and Knobel, 2006; Sun, 2018); (3) movies (Sun, 2018); (4) television series (Caffrey, 2009); and (5) cartoons (Thalle, 2009; Yegulalp, 2018). Japanese animation has also attracted audiences from multiple cultures within various genres, i.e. horror, fiction, comedy, adventure, and drama (Steine, 2019). Thus, children have engaged extensively with Naruto and Bleach (Drummond-Mathews, Dallas, \& Scally, 2019), My Neighbor Totoro, Pokémon, and Doraemon, whilst young adult viewers have been drawn to Inuyasha, Death Note, and Attack on Titan (Yegulalp, 2018). Due to the popularity of Japanese animation, audiences are willing to engage 
even when such productions are subtitled (Caffrey, 2009; Howell 2007; Corpuz, 2020) or dubbed (Mas Lopez 2004; Adachi 2012; Lunning, 2006).

The first Japanese anime televised series in Japan was Astro Boy, created by Osamu Tezuka in 1963 (David, 2014). More recently, Japanese anime have recently gained popularity in the Middle East and in Saudi Arabia in particular. The Journey, released in 2021, was the first Japanese-Saudi animated film co-produced by Toei Animation and Manga Production, following and the training of 300 young Saudi in the art of manga in Japan. Taking two and half years to produce, the story revolves around the attempts of a potter known as Aws to defend his city (Al-Kinani, 2021).

\subsection{Background to Attack on Titan}

From 2013 to the present, the most globally popular Japanese animation has been Attack on Titan (Shingeki no Kyojin) (Willcocks, 2017; Yahuda, 2013; Thelen, 2020), which ran to four seasons in both English and Japanese, being both subtitled and dubbed. The main antagonists in this manga and anime are Titans, described by Willcocks (2017) as massive humanoid beings that have driven humankind to extinction, being predominantly male humans with no sexual organs and some disfigurements, i.e. bloated heads (Isayama, 2010). In addition, Willcocks (2017) pointed out that the main aim of the Titans is to consume, and destroy humans, ignoring alternative sources of nutrition as they have survived for 100 years without eating any kind of life other than humans. In the manga and anime, the Titan are classified into three groups, based on their appearance, behaviour, and unpredictable actions, who can choose particular targets to strike and can execute actions such as moving and jumping. Alongside these are Titan Shifters ('Shifters'), who are humans capable of turning into Titans (Willcocks \& Parry, 2017).

Most of the existing literature reviews focused on Attack on Titan are undertaken from a cultural perspective. It should be noted that reviews from a variety of different cultures are distinctive from those originating from Japan, despite consuming Japanese animation. Thus, Drummond-Mathews, Dallas, and Scally (2019) stated that American audiences have undertaken a positive interaction with Japanese animation due to identifying with characters unable to exert control over their own feelings or strength, concluding that: '[an] American audience would be expecting answers, or at least a clue, Attack on Titan leaves viewers with only more questions' (Drummond-Mathews, Dallas, and Scally, 2019, p.8). This indicates that the spectator must share the characters' fear of an inevitable attack or death, as well as the unease that comes from being unable to understand why such attacks are taking place. However, Levi (2001) opposed this concept of the influence of Japanese animation, stating that "[a]nime and manga are still largely targeted exclusively at a Japanese market, without much consideration for the international market it actually enjoys." (Levi, 2001, p. 156). In addition, Caffrey (2009), indicated that audiences in North America exert little influence over Japanese producers.

A study by Meng and Yu (2019) considered this phenomenon from an Asian cultural proximity perspective, examining the motivation of Chinese viewers for watching Japanese animation, as well as their enjoyment. The study also investigated the impact of cultural proximity on culture and that of genre familiarity on viewing motivation and satisfaction. Meng and Yu (2019) employed an online questionnaire with 162 Chinese participants, who were regular viewers of Japanese animation for the following reasons: (1) to "learn something"; (2) a "habitual pastime"; (3) "an interest in the content of anime"; and (4) "appeal for inter-personal interaction".

The study also found that the Chinese viewers watched Japanese animation as a means of understanding Japanese culture, concluding that the cultural proximity of China to Japan, as well as genre experience with Japanese animation, influenced a wide range of viewing motives and satisfaction levels. Additionally, a study by Saputra, Bunau, and Wardah (2019) examined the relationship between students' frequency of viewing Attack on Titan and their reading comprehension during a third-semester Intensive English Study Programme at Tanjungpura University, during the academic year 2018-2019. The study applied the correlation method with thirty students, identifying that the frequency at which participants watched Attack on Titan correlated positively with their reading comprehension.

The existing literature has emerged from a variety of cultures, with the spectrum covering Western, Asian and Middle Eastern North African countries (MENA). For instance, an Algerian study undertaken by Sabri (2019) examined the idea that the song at the start of the animation supports the seismological approach, as the entrance depends on semantics and implied meanings. The study employed Roland Barth's approach as an essential method, as well as that of researcher Martin Jolie as an empathetic approach. These proved practical means of examining a specific sample of dubbed Japanese cartoon characters, with Sabri (2019) selecting mothers on Facebook based to their survey position. The study found that positive values emerged from watching the animation (i.e. cooperation; love and sacrifice; stability; and optimism), as well as a number of negative impacts 
(i.e. aggression, vengeance, and brutality).

The review of the existing body of literature discussing Japanese animation (either generally or focussing on specific examples) revealed that few previous studies have investigated the impact on Arabic viewers of watching Japanese animation such as Attack on Titan, and in particular the perceptions of young Saudi viewers who tend to be those interacting with Japanese animation. From the cultural perspective, it can be surmised that exposure to Japanese animation such as Attack on Titan has the potential to influence the perceptions, social norms and cultural values of a Saudi audience. Lamarre stated that: ' $[\mathrm{h}] \mathrm{ow}$ we view and process media like anime have strongly influenced how we interact with, and evaluate, information in general' (Lamarre, 2002, p. 337). Thus it can be concluded that exposure to Attack on Titan could impact the perceptions of young Saudi viewers, resulting in increased engagement with this animation.

This current study therefore addresses this gap by examining the impact on the perceptions of young Saudis of watching Attack on Titan, due to this age-group being targeted by Japanese animation, i.e. '[y]ounger audiences as its target market' (Steine, 2019, p. 1)

A recent study investigating the correlation between watching Attack on Titan and the reading comprehension levels of thirty students, identified a positive correlation between the frequency of watching this anime and reading comprehension scores (Saputra, 2019). In response to this conclusion, the current study also investigated whether the respondents' interest in reading the story increased after watching the anime.

\section{Method}

This study used a quantitative approach, due to no previous research having been conducted on a Saudi audience of Japanese animation, thus highlighting a need to create an understanding from a large audience. Burns and Grove (1993) noted that quantitative approach is a systematic, formal and objective process of testing the relationships between variables. The researchers employed a survey to collect data from the respondents, with information gathered through an electronic link, which was distributed through the networks of both researchers.

\subsection{Sample}

The sample of this study consisted of 346 individuals who regularly watched the animation Attack on Titan, aged between fourteen and thirty-eight. The majority of respondents were female (70\%), with $30 \%$ being male. Due to the Covid-19 global pandemic resulting in a limited interaction in the workplace, along with the lack of social gatherings, the researchers used network sampling to reach as many anime lovers as possible, and in particular those who watched the Attack on Titan series.

Network sampling uses social, workplace, or community networks for locating and recruiting the study participants (Davis et al., 2013, p. 164). Thus, network sampling was found to be a useful strategy for this research as potential participants were more willing to join when approached by an individual they knew and trusted rather than a participant in a research project.

\subsection{Statistical Analysis}

The data was analyzed using SPSS version 25, employing coefficient Cronbach's Alpha to test the reliability of the questionnaire, along with the descriptive statistics, i.e. frequency and percentage and mean and standard deviation. In addition, Spearman's rho test was used to study the correlation between variables.

First validity and reliability analysis of the study

Table 1. Reliability Test

\begin{tabular}{ccc}
\hline & Reliability Statistics & \\
\hline Cronbach's Alpha & N of Items \\
\hline .769 & 38 \\
\hline
\end{tabular}

Table 1 illustrates the value of the coefficient of Cronbach's alpha, which is equal to 0.769, and reflects positively on the results of this study. This indicates that the questionnaire achieved its goals by $76.9 \%$

Second: Descriptive statistics

1. What's your gender? 


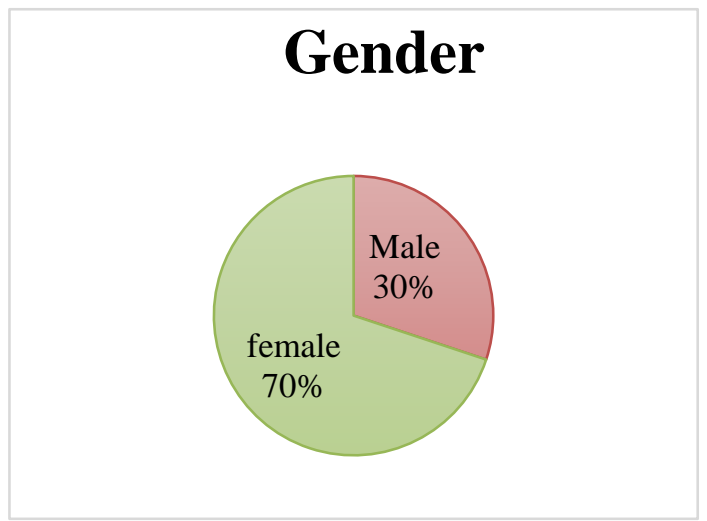

Figure 1. Gender

As illustrated in Figure 1 (above), the majority of respondents (70.0\%) were female, thus confirming that two thirds of the sample were female, with male viewers forming one third.

2. How old are you?

Table 2. Participants age range

\begin{tabular}{cc}
\hline Age & Percent \\
\hline $14-19$ years old & $26.9 \%$ \\
$20-25$ years old & $63 \%$ \\
$26-30$ years old & $6.1 \%$ \\
$31-35$ years old & $2.9 \%$ \\
More than 36 years old & $1.2 \%$ \\
\hline
\end{tabular}

Table 2 (above) indicates that most of the respondents who watched the anime were aged between twenty and twenty-five. The second group consisted of viewers aged between fourteen and nineteen $(26.9 \%)$ and the third group consisted of respondents aged between twenty-six and thirty (6.1\%). There were only a small number of respondents aged over thirty-one who stated that they viewed the series $(4.1 \%)$. This implies that the main viewers of Japanese anime are teenagers and young adults aged between fourteen and twenty-five.

3. What is your educational level?

The majority of the respondents consisted of university students, who formed $72 \%$ of the sample. The second group was made up of high school students $(14 \%)$, while those expressing the least interest in the series were postgraduate and intermediate stage students.

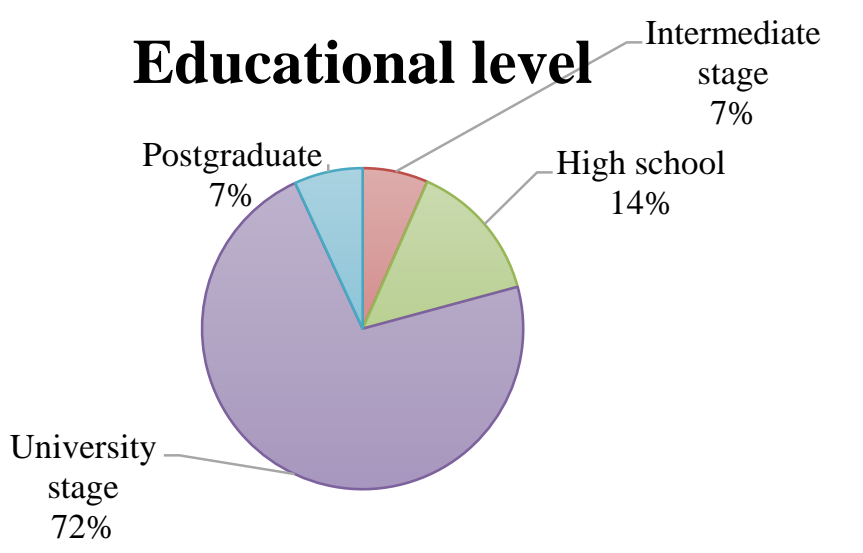

Figure 2. Sample educational level 
4. What is the most prominent Japanese anime you watch?

This study found that 312 respondents identified Attack on Titan as their most popular anime. Second was Naruto (224 respondents, i.e. 10.17\%) (see Figure 3); the third was Hunter X Hunter (218 respondents); and the fourth was One Piece (208 respondents). The participants were also asked to indicate if they enjoyed more than anime, which lead to 2203 responses, with $88 \%$ of the participants choosing this option.

\section{The most prominent Japanese anime}

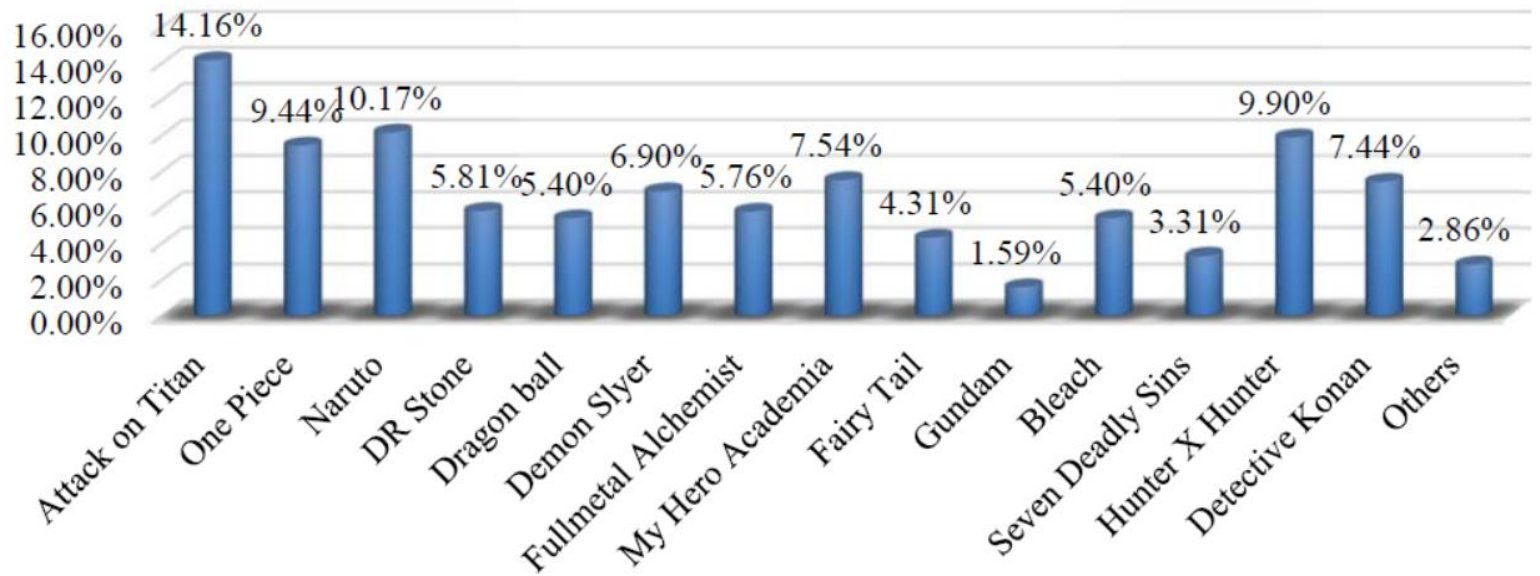

Figure 3. The most prominent Japanese anime

As illustrated in Figure 3, the less popular animes under the category of "others" were: (1) One Punch Man; (2) Jujutsu Kaisen; (3) Death Note; and (4) The Promised Neverland. One of the least liked was Gundam, as indicated by $1.59 \%$ of the sample. Animes evaluated as average included: (1) My Hero Academia; (2) Demon Slayer; (3) Fullmetal Alchemist; (4) Dragon ball; and (5) Dr Stone.

5. How do you like to watch Japanese animation?

Table 3. Dubbing and translation options

\begin{tabular}{cc}
\hline How do you watch & Percent \\
\hline Dubbed into English & $4.9 \%$ \\
Translated into Arabic & $75.1 \%$ \\
English subtitles & $16.8 \%$ \\
Without dubbing & $3.2 \%$ \\
\hline
\end{tabular}

The majority $(75 \%)$ of the sample, were non-Japanese speakers, who therefore relied on the Arabic translation to understand the scenario and dialogue. However, 3.2\% understood Japanese and therefore watched the anime without translation or dubbing to another language, and approximately 17\% preferred English subtitling, while $4.9 \%$ used the version dubbed into English.

6. How many hours do you watch Japanese animation each day?

Figure 4 (below) demonstrates that approximately $76 \%$ of the respondents watched anime for between one and three hours a day, with $38 \%$ viewing for one hour, while the remaining $38 \%$ viewed it for between two and three hours daily.

In addition, the sample included a small proportion of viewers (4\%) who watched anime for over hours daily, while approximately $11 \%$ of the respondents watched for over four hours daily. 


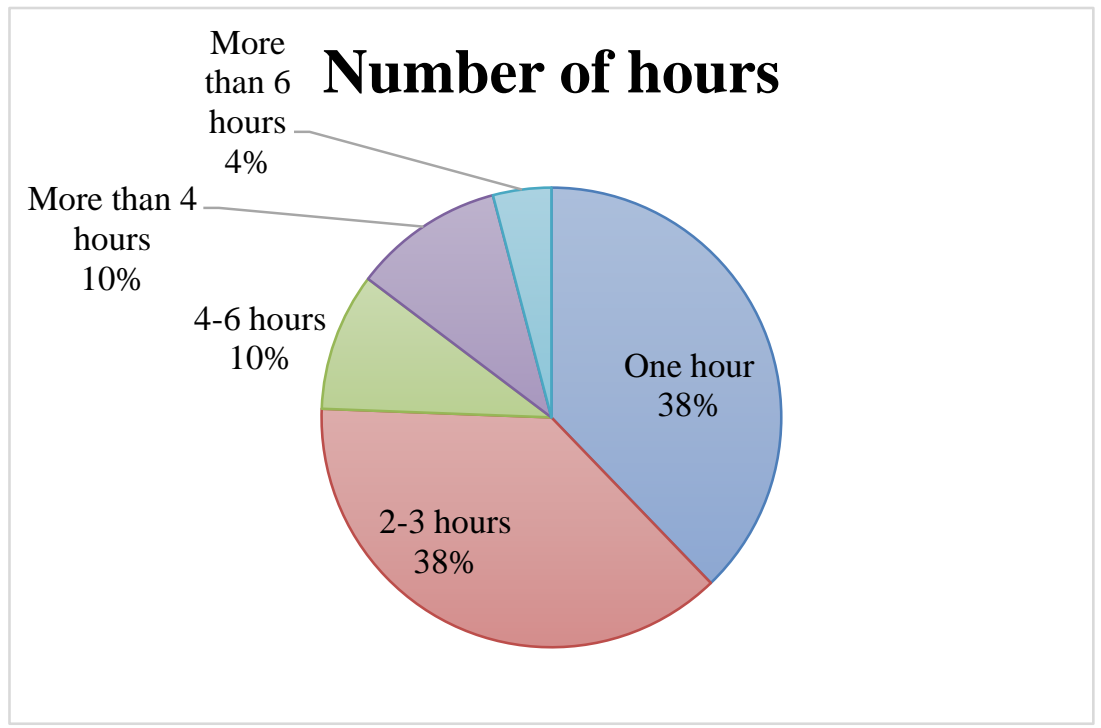

Figure 4. hours of watching Attack on Titan daily

7. What digital platform do you use when watching Japanese animation?

Figure 5 (below) demonstrates that 33\% of the sample watched Attack on Titan on Anime Cloud, with the second most popular platform being Netflix (131 viewers, i.e. $18.17 \%$ of the overall sample). The third most popular platform was YouTube (95 viewers, i.e. 13.18\% of the sample). The least popular platforms were websites such as Kiss Anime, Gogoanime, and Animualtima.

\section{The platform used to watch Japanese anime}

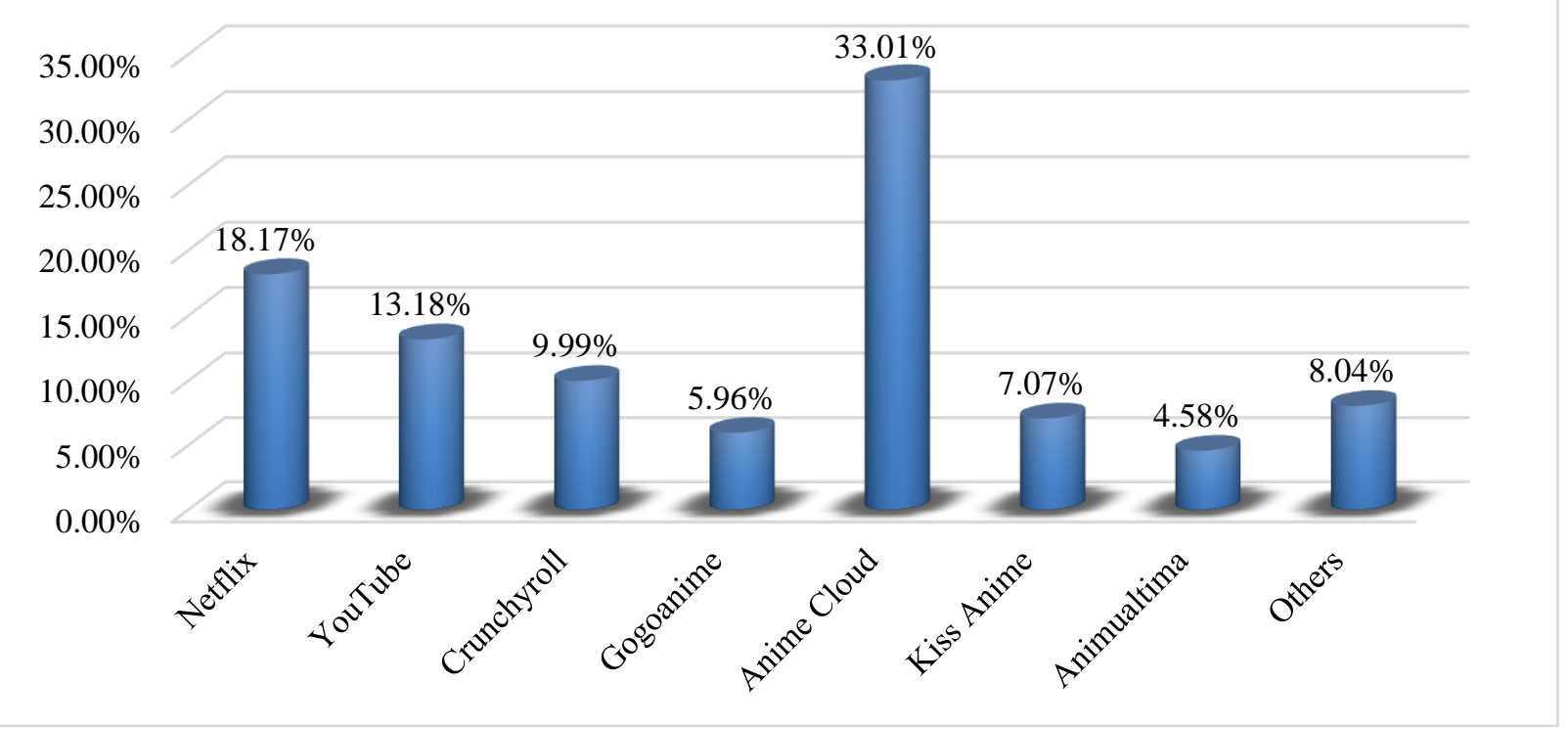

Figure 5. The platform used to watch Japanese anime

8. How did you know about Japanese anime?

As demonstrated in Table 4, most of the respondents (40\%) had found out about the anime from "A friend's suggestion" with $21 \%$ having been introduced through social media accounts. In addition, the participants had learnt about the anime from TV and the Google search engine. However, the table also reveals that advertisements on YouTube and games did not play any significant role in promoting the anime compared to other social media platforms and the influence of friends. 
Table 4. Source of knowing the anime

\begin{tabular}{cc}
\hline I got to know the anime through & Percent \\
\hline Social media accounts & $21.20 \%$ \\
A friend's suggestion & $40.40 \%$ \\
The Google & $10.50 \%$ \\
the family & $6.70 \%$ \\
Read printed stories & $6.40 \%$ \\
TV & $11.60 \%$ \\
PlayStation games & $0.60 \%$ \\
YouTube & $0.60 \%$ \\
By myself & $2 \%$
\end{tabular}

9. What is your opinion of Japanese anime?

Table 5 demonstrates that most of the respondents chose the option "Strongly agree" when it came to the following statements: (1) 'I watch Japanese animation for fun'; (2) 'I watch Japanese animation for leisure'; (3) 'I don't feel the passage of time when watching Japanese animation'; (4) 'I like the supernatural abilities of characters, like flying'; (5) 'I like Japanese texts and letters'; (6) 'I am attracted by creativity in the direction of the series Attack on Titan'; (7) 'The scenario and story of Attack on Titan series are distinct'; (8) 'The series is characterized by a departure from the ordinary compared to the local series'; (9) 'I like the tone of voice and the manner of speaking used by the characters'; and (10) 'I am attracted by the anime's facial expressions and emotions'. In addition, they selected "Agree" for 'I like the Japanese culture that appears in Attack on Titan', "Neutral" for 'I prefer reading manga stories beforehand before watching next season' and "Disagree" for 'I watch Attack on Titan because my friends do'.

Table 5. Perceptions of Japanese anime

\begin{tabular}{|c|c|c|c|}
\hline Items & Mean & $\begin{array}{c}\text { Std. } \\
\text { Deviation }\end{array}$ & Results \\
\hline I watch Japanese animation for fun & 4.815 & 0.470 & Strongly agree \\
\hline I watch Attack on Titan because my friends do & 2.497 & 1.419 & Disagree \\
\hline I am watching Japanese animation to spend free time & 4.214 & 1.007 & Strongly agree \\
\hline I don't feel the passage of time when watching Japanese animation & 4.509 & 0.807 & Strongly agree \\
\hline I like the supernatural abilities of characters like flying & 4.217 & 0.943 & Strongly agree \\
\hline I like Japanese texts and letters & 4.327 & 0.898 & Strongly agree \\
\hline $\begin{array}{l}\text { I am attracted by creativity in the direction of the series Attack on } \\
\text { Titan }\end{array}$ & 4.653 & 0.723 & Strongly agree \\
\hline The scenario and story of Attack on Titan series are distinct & 4.714 & 0.639 & Strongly agree \\
\hline I like the Japanese culture that appears in Attack on Titan & 4.049 & 1.177 & Agree \\
\hline $\begin{array}{l}\text { The series is characterized by a departure from the ordinary compared } \\
\text { to the local series }\end{array}$ & 4.494 & 0.849 & Strongly agree \\
\hline I like the tone of voice and the manner of speaking the characters use & 4.711 & 0.670 & Strongly agree \\
\hline I am attracted by the anime's facial expressions and emotions & 4.676 & 0.650 & Strongly agree \\
\hline I prefer reading manga stories beforehand before watching next season & 2.971 & 1.541 & Neutral \\
\hline
\end{tabular}

10. What is your opinion of Japanese culture?

As illustrated in Table 6, most of the respondents chose "Strongly agree" for: (1) 'I learned some Japanese words from series'; (2) 'I Feel integrated with the characters when watching Japanese animation'; (3) 'Watching Japanese animation motivates me to visit Japan'; and (4) 'I am listening to Japanese animation music'. In 
addition they chose "Agree" for: (1) 'I would like to belong to Japanese culture'; (2) 'I would like to speak to my friends in Japanese'; (3) 'I would like to eat Japanese food and I know some types of foods'; (4) 'I mimic the manner of speech and tone with which they challenge Attack On Titan characters'; (5) 'Watching Attack on Titan motivates me to read manga'; (6) 'When watching Attack on Titan, I feel that I am part of the series and in the same place'; (7) 'I bought some Japanese stuff after watching the series'; and (8) 'Watching Attack on Titan motivated me to watch other Japanese series'.

Table 6. Viewers' perceptions of Japanese culture

\begin{tabular}{llcc}
\hline Items & Mean & Std. Deviation & Results \\
\hline I would like to belong to Japanese culture & 3.460 & 1.325 & Agree \\
I would like to speak to my friends in Japanese & 3.688 & 1.292 & Agree \\
$\begin{array}{l}\text { I learned some Japanese words from series } \\
\text { I Feel integrated with the characters when watching Japanese } \\
\text { animation }\end{array}$ & 4.431 & 0.796 & Strongly agree \\
Watching Japanese animation motivates me to visit Japan & 4.445 & 0.792 & Strongly agree \\
$\begin{array}{l}\text { I would like to eat Japanese food, and I know some types of } \\
\text { foods }\end{array}$ & 4.185 & 1.162 & Strongly agree \\
$\begin{array}{l}\text { I mimic the manner of speech and tone of the characters in } \\
\text { Attack on Titan }\end{array}$ & 3.754 & 1.412 & Agree \\
$\begin{array}{l}\text { I am listening to Japanese animation music } \\
\text { Watching Attack on Titan motivates me to read manga }\end{array}$ & 4.335 & 1.081 & Agree \\
$\begin{array}{l}\text { When watching Attack on Titan, I feel that I am part of the } \\
\text { series and in the same place }\end{array}$ & 3.855 & 1.473 & Agree \\
$\begin{array}{l}\text { I bought some Japanese stuff after watching the series } \\
\text { Watching Attack } \text { on Titan motivated me to watch other Japanese } \\
\text { series }\end{array}$ & 3.081 & 1.255 & Agree \\
\hline
\end{tabular}

11. What scenes in the series attract you?

The data indicated that viewers were primarily attracted to scenes that included fighting and conversation. In particular, approximately $19 \%$ of the sample enjoyed the fight scenes between Titans and humans, while $14 \%$ experienced the fencing scenes as engaging. Furthermore, approximately $14 \%$ enjoyed the scenes that included conversation and dialogue. This finding was consistence with Table 5, in which participants referred to the characters' voices and manner of speaking as one of the elements they liked about the anime. The participants also referred to other types of scenes they found enjoyable, which tended to include violence, i.e. scenes of destruction and flying blood.

Table 7. The most attracting scenes

\begin{tabular}{ccc}
\hline Anime & Count & $\%$ \\
\hline Fighting with swords (fencing) & 215 & $14.42 \%$ \\
Scenes of flying blood & 157 & $10.53 \%$ \\
The appearance of the Giants and their destructiveness & 169 & $11.33 \%$ \\
Fighting between giants and humans & 280 & $18.78 \%$ \\
Scenes of destruction & 145 & $9.73 \%$ \\
Giants running in the city and the forest & 145 & $9.73 \%$ \\
Dialogue Scenes & 202 & $13.55 \%$ \\
Giants devouring humans & 150 & $10.06 \%$ \\
Others & 28 & $1.88 \%$ \\
Total & 1491 & $100.00 \%$ \\
\hline
\end{tabular}


12. Who is your favorite character?

As highlighted in Table 8, the data reported that the most liked characters were Levi, Erin, and Mikasa. Although Erin is the main character, only $38 \%$ of the participants' ranked him as their favorite character while $15 \%$ indicated Erin and $16 \%$ Mikasa. This might be seen as arising from Levi being a strong fearless leader, who always wins his battles with Titans and never expresses hesitation or weakness throughout the three seasons. Similarly, Mikasa is a female figure who continuously defends Erin and has exceptional fighting skills. On the other hand might viewers' opinions of Erin may have been influenced by the fact that, despite his considerable potential and skills, he tends to express weakness and sadness in critical moments (i.e. when Titans were about attack the whole city). In addition, when it came to the least liked characters, the participants identified the Armorer Titan, the Female Titan, Sasha, and Christa. This thus raises the issue of the least liked characters being all female, and regardless of the extraordinary skills of the female Titan.

Table 8 . The most liked characters

\begin{tabular}{cc}
\hline Character & Percent \\
\hline ANNIE & $1.70 \%$ \\
EREN TITAN & $3.50 \%$ \\
ERIN & $14.70 \%$ \\
JAW TITAN & $0.90 \%$ \\
ARMORED TITAN & $0.30 \%$ \\
LEVI & $37.90 \%$ \\
MIKASA & $15.90 \%$ \\
COLOSSAL TITAN & $1.40 \%$ \\
FEMALE TITAN & $0.30 \%$ \\
IRWIN & $5.80 \%$ \\
BERT & $0.90 \%$ \\
JEAN & $3.50 \%$ \\
HANJE & $4.60 \%$ \\
ARMIN & $4 \%$ \\
REINER & $3.50 \%$ \\
SASHA & $0.60 \%$ \\
CHRISTA & $0.60 \%$ \\
\hline
\end{tabular}

\section{Hypothesis Tests}

1. Studying the relationship between gender and the study variables

Table 9 concludes the existence of a weak relationship between gender and the following variables: (1) 'The most prominent Japanese anime watched'; (2) 'I like Japanese texts and letters'; (3) 'I learned some Japanese words from series'; (4) 'I feel integrated with the characters when watching Japanese animation'; (5) 'Watching Japanese animation motivates me to visit Japan'; (6) 'I would like to eat Japanese food and I know some types of foods'; (7) 'When watching Attack on Titan, I feel that I am part of the series'; (8) 'I bought some Japanese stuff after watching the series'; and (9) Favorite character. In addition, there was no relationship identified between gender and the remainder of the variables, with this weak correlation indicates the presence of a minimal relationship. It should be noted that this may have arising from the fact that $70 \%$ of the respondents are females while only $30 \%$ were the males.

Table 9. Using Spearman's rho test

\begin{tabular}{ll}
\hline Items & Gender \\
\hline The most prominent Japanese anime you watch & $.156^{*}$ \\
I like Japanese texts and letters & $-.114^{*}$ \\
I learned some Japanese words from series & $-.109^{*}$ \\
Feel integrated with the characters when watching Japanese animation & $-.190^{*}$ \\
Watching Japanese animation motivates me to visit Japan & $-.184^{*}$ \\
I would like to eat Japanese food, and I know some types of foods & $-.218^{*}$ \\
\hline
\end{tabular}


When watching Attack on Titan, I feel that I am part of the series

$-.171^{*}$

I bought some Japanese stuff after watching the series

Favorite character

$-.109 *$

2. The relation between age and the study variables

As indicated in Table 10 (below), the data found a weak relationship between age and the following variables: (1) 'Duration of watching anime'; (2) 'The way I got to know the anime'; (3) 'I do not feel the passage of time when watching Japanese animation'; (4) 'I prefer reading manga stories beforehand before watching next season'; (5) 'I would like to belong to Japanese culture'; (6) 'Watching Japanese animation motivates me to visit Japan'; (6) 'I would like to eat Japanese food, and I know some types of foods'; (7) 'The attractive scenes' and (8) Favorite character. This study also found no relationship between age and the remainder of the variables, i.e. although the statistical analysis proposed a relationship between age and other variables, the results confirmed that this was weak. This indicates that the independent variable "age" was not essential for predicting other variables, as they did not reach a statistically significant meaning. This could be explained by the fact that manga series tend to attract audiences from a wide age range. As highlighted earlier in Table 2, this study confirmed that Attack of Titan was watched by an audience as young as fourteen, and older than thirty-six.

Table 10. Using Spearman's rho test

\begin{tabular}{cc}
\hline Items & Age \\
Duration of watching anime & $.232^{*}$ \\
The way I got to know the anime & $.126^{*}$ \\
I do not feel the passage of time when watching Japanese animation & $-.133 *$ \\
I prefer reading manga stories beforehand before watching next season & $.162 *$ \\
I would like to belong to Japanese culture & $.154 *$ \\
Watching Japanese animation motivates me to visit Japan & $.144 *$ \\
I would like to eat Japanese food, and I know some types of foods & $.108 *$ \\
The attractive scenes & $-.156^{*}$ \\
Favorite character & $.181 *$ \\
\hline
\end{tabular}

3. Studying the differences between favorite anime characters and gender

The null hypothesis assumed a significant difference between favorite anime characters based on gender, i.e. whether viewers demonstrated a tendency to prefer male or female characters. However, Table 11 shows that the p-value is equal to 0.042 , which is less than 0.05 , resulting in the researchers accepting the null hypothesis of a significant difference between favorite anime characters between females and males. Consequently, we have rejected the alternative hypothesis indicating the presence of no significant differences between favorite anime characters between females and males.

Table 11. Using Mann-Whitney U test

\section{Test Statistics}

favorite anime character

Mann-Whitney U

Wilcoxon $\mathrm{W}$

Z

Asymp. Sig. (2-tailed)
10904.000

16364.000

$-2.033$

.042

a. Grouping Variable: gender

This hypothesis was consistent with the participants' responses when asked about their favorite character in 
Attack on Titan, as illustrated in Table 8 earlier. Two of the most popular characters (Levi and Erin) were male, with Mikasa (a female character with excellent fighting skills) also appearing among the three most liked characters. Therefore, the ratio indicates that these viewers tended to prefer male to female characters in Attack on Titan.

This outcome is supported by Ahmed and Wahab's (2014) investigation of the gender depiction of both male and female characters in animated cartoons broadcasted from the Cartoon Network in different Asian and pacific countries (i.e. Japan, Australia, Pakistan, Taiwan, Malaysia, Korea and India) The study conducted content analysis on popular Japanese animations (i.e. Ben 10; Scooby Dooby Doo; Tom and Jerry; Pokémon; Bakugan; Thunder Cats; Power Puff Girls; Dragon Ball Z; Generator Rex; and Batman) broadcast between January and July 2013. The results revealed that Japanese animation portrayed the female characters as negative stereotypes (i.e. physically weak, dressed in a sexual manner, attractive, and dependent), whilst the males characters were portrayed as positive stereotype (i.e. brave, strong, intelligent, and dominant).

In Attack on Titan, there are only two strong female characters (i.e. Mikasa and the female Titan), with the remainder portrayed as being in need of masculine help and less capable than men. Thus, the data reported that viewers are mostly interested in male characters and female characters who appear capable, strong, independent, and brave.

\section{Discussion}

This study focused on understanding Saudi viewers' perceptions of the Japanese anime known as Attack on Titan. The study participants were $70 \%$ female and $30 \%$ male, with the majority being university students aged between twenty and twenty-five. As most were non-Japanese speakers, the majority (75\%) watched through an "Arabic translation". This result was supported the research undertaken by Alsubaie and Alabbad (2020), who investigated the impact of Japanese animation in the context of casual third language acquisition. The study applied an online survey questionnaire with 215 participants aged between fifteen and thirty-five from fourteen diverse countries, including Saudi Arabia and Kuwait, concluding that $87 \%$ preferred to watch Japanese Anima with Arabic subtitles.

In terms of viewing time, $38 \%$ respondents viewed the anime for one hour daily, with the remaining $38 \%$ viewing it for between two and three hours daily. Thus approximately $76 \%$ of the respondents were medium viewers, although $4 \%$ of the sample were found to watch the anime for over six hours daily, while approximately $11 \%$ watched for more than four hours daily. The participants were found to mainly watch the anime on Anime Cloud, Netflix, or YouTube, and the majority had heard about the series from friends' networks or social media platforms.

The participants were found to be mostly attracted to fight scenes, as well as those that included dialogue, and they tended to repeat-view these scenes. The viewers stated that they watched Japanese animation for leisure and fun and to pass the time, indicating that Saudi audiences may use them to pass time, to distract themselves, and to experience pleasure. Sherry noted that '[For] Csikszentmihalyi, enjoyment, as realized in the flow state, is an "autotelic" or self-motivating experience characterized by distortion of temporal experience (typically, a sense that time has passed faster than normal)' (Sherry, 2004, p.331-332).

Viewers identified those elements attracting them to the series as including: firstly, the supernatural abilities of characters (i.e. flying); secondly, Japanese text and letters; thirdly, the creativity of the scenario and the story; fourthly, the characters' tone of voice and manner of speaking; and fifthly, their facial expressions and emotions. They also felt that these elements distinguished the anime from local productions.

This research found that viewers' attraction to the anime also influenced their lifestyle and perception of Japanese culture, i.e. motivating them to visit Japan, listen to Japanese music, read manga and eat Japanese food. Additionally, the participants revealed that they sometimes mimicked the manner of speech and tone of the anime characters. The concept of the impact of Japanese culture was confirmed by a Lebanese study undertaken by El Mufti (2020), who examined the influence of watching Grendizer, i.e. one of the most popular animation from the 1970s, particularly among Arabic viewers from Jordan, Egypt, Saudi Arabia and other Gulf countries. The study attempted to identify why Grendizer left such an indelible imprint on the minds and hearts of a generation of children, who saw in the character a superhero figure offering an escape route from the difficulties in their own lives. This can be seen as responding to the wars taking place in the Middle Eastern region during the 1970s. Furthermore, the study analyzed the influence of these Japanese cultural reference on Arabic audiences, highlighting how the animation was domesticated for an Arab context, leaving its native universe and encompassing the thinking, sentiments, and aspirations of several Arab generations. 
This study also found viewers of Attack on Titan were most attracted to those skilled at fencing and with strong personalities, i.e. Leader Levi and Mikasa. About 38\% of the sample indicated that Levi was the most liked character while $16 \%$ preferred Mikasa. However, a significant number (14\%) of the participants ranked main protagonist, Erin, as only the third most liked character.

The weak relationships between age and gender and the other variables indicated that these were not as important when it came to predicting these variables. Additionally, these correlations may have arisen due to the study sample focuses on females and a particular age group. This study therefore recommends that future researchers should incorporate content analysis alongside the survey in order to obtain insights into the codes and the relationship between the variables.

\section{References}

Adachi, R. (2012). A study of Japanese animation as translation: A descriptive analysis of Hayao Miyazaki and other anime dubbed into English. Universal-Publishers.

Ahmed, S., \& Wahab, J. A. (2014). Animation and socialization process: Gender role portrayal on cartoon network. Asian Social Science, 10(3), 44. https://doi.org/10.5539/ass.v10n3p44.

AJA. (2018). Anime Industry Data. The Association of Japanese Animations. Retrieved May 7, 2017, from https://aja.gr.jp/english/japan-anime-data,pdf Anime Industry Report 2017 Summary (Revision)

Al-Kinani, M. (2021). Saudi behind 'The Journey' anime trained in Japan. Arab News.

Alsubaie, S. S., \& Alabbad, A. M. (2020). The Effect of Japanese Animation Series on Informal Third Language Acquisition among Arabic Native Speakers. English Language Teaching, 13(8), 91-119. https://doi.org/10.5539/elt.v13n8p91

Brown, S. T. (Ed.). (2006). Screening Anime. In Cinema Anime: Critical Engagements with Japanese Animation. New York: Palgrave Macmillan.

Caffrey, C. (2009). Relevant abuse? Investigating the effects of an abusive subtitling procedure on the perception of TV anime using eye tracker and questionnaire. Unpublished PhD: Dublin City University

Corpuz, L. J. R. (2020). Anime with English Subtitles. Tool in Expanding Second Language Learners' Vocabulary and Syntactic Complexity. International Journal of Novel Research in Education and Learning, 7(5), 1-13.

David, F. A. (2014). Differences between Japanese and Western anatomical animation techniques applied to videogames. Unpublished BA thesis: University peritectic De Catalunya Barcelonatech.

Davis, C., Powell, H., \& Lachlan, K. (2013). Straight talk about communication research methods. Dubuque: Kindle Hunt Publishing

Drummond-Mathews, A., Dallas, U. N. T., \& Scally, D. (2019). A Phenomenology of Americans and Anime: How Tropes Predict Experience. The Phoenix Papers, 1(2), 1-9.

El Mufti, K. (2020). Influence and success of the Arabic edition of UFO Robo Grendizer: Adoption of a Japanese icon in the Arabic-speaking world. Mutual Images Journal, (9), 3-37. https://doi.org/10.32926/2020.9.ELM.GREND.

Howell, P. (2007). Character voice in anime subtitles. Perspectives, 14(4), 292-305. https://doi.org/10.1080/09076760708669045.

Isayama, H. (2010). Attack on Titan, Japan. USA: Kodansha America Inc.

Lamarre, T. (2002). From Animation to Anime: Drawing Movements and Moving Drawings. Japan Forum, 14(2), 337. https://doi.org/10.1080/09555800220136400.

Lankshear, C., \& Knobel, M. (2006). New Literacies: Everyday Practices and Classroom Learning (2nd ed.). Maidenhead: Open University Press.

Levi, A. (2006). The Americanization of anime and manga: Negotiating popular culture. In S. Brown (Ed.), Cinema Anime (pp. 43-46). New York: Palgrave Macmillan. https://doi.org/10.1057/9781403983084_3.

Lovegren, S. (2003). Cartoons for grown-ups, Japan's anime draws millions. National Geographic News. Retrieved from http://news.nationalgeographic.com/news/2003/09/0916_030916_milleniumactress.html

Lunning, F. (Ed.). (2006). Emerging worlds of anime and manga (Vol. 1). U of Minnesota Press.

Mas Lopez, J. (2004). From Tokyo to Barcelona, translating Japanese anime into Catalan. The Globalization 
insider. Online 9. Retrieved from http://www.lisa.org/globlizationinsider/2004/09/form_to_b.html

Meng, Y., \& Yu, S. K. (2019). Uses and Satisfaction Afforded by Japanese Animation to Chinese Audiences. Asian Journal of Journalism and Media Studies, 2, 28-43. https://doi.org/10.33664/ajjms.2.0_28

Natsume, F. (2000). Japan's manga culture. The Japan Foundation Newsletter, 27(3/4), 1-6.

Ruh, B. (2014). Conceptualizing anime and the database fantasyscape. Mechademia, 9, 164-175. https://doi.org/10.1353/mec.2014.0012.

Sabri, R. (2019). Values in Japanese dubbed cartoon characters. Unpublished MA thesis: Larbi Ben M'hidi University Oum El-Bouaghi.

Saputra, T. (2019). Correlation study between frequency of watching "Attack on Titan" and reading comprehension. Jurnal Pendidikan dan Pembelajaran Khatulistiwa, 8(6).

Sherry, J. L. (2004). Flow and media enjoyment. Communication theory, 14(4), 328-347. https://doi.org/10.1111/j.1468-2885.2004.tb00318.x.

Steine, I. M. (2019). Anime in Tourism: An Analysis of Norwegian Anime Enthusiasts' Motivation for Conducting Anime-Induced Travels to Japan. Published MA thesis: UIT The Arctic University of Norway.

Sun, P. (2018). Primary Exploration on the Differentiation of the Animation Industry Models of China, Japan, and America in the Context of the Two-dimensional Culture. Advances in Social Science, Education and Humanities Research, volume 289,5th International Conference on Education, Language, Art, and Inter-cultural Communication (ICELAIC 2018).

Thelle, A. (2009). Anime - Hva er det? Oslo: Omnipax

Tongdhamachart, N. (2015). Japanese Animation: Thailand's Perspective. International Journal of Arts \& Sciences, 8(2), 129.

Willcocks, L. (2017). Could Titans Produce Enough Energy to Sustain Themselves? Journal of Interdisciplinary Science Topics, 1-4.

Willcocks and Parry (2017).

Yahuda, M. (2013). Sino-Japanese relations after the Cold War: Two tigers sharing a mountain. Routledge.

Yegulalp, S. (2018). An Introduction to Anime: What You Should Know About Japanese Animation. Thought Co. Retrieved February 26, 2019, from https://www.thoughtco.com/what-is-anime-144982

\section{Copyrights}

Copyright for this article is retained by the author(s), with first publication rights granted to the journal.

This is an open-access article distributed under the terms and conditions of the Creative Commons Attribution license (http://creativecommons.org/licenses/by/4.0/). 